\title{
Obituary
}

\section{Professor Robert Roaf (25 April 1913 to 16 February 2007)}

\author{
Spinal Cord (2007) 45, 534; doi:10.1038/sj.sc.3102085
}

Professor Roaf was an eminent, innovative orthopaedic surgeon whose long, distinguished career covered all aspects of the treatment of spinal disorders. Apart from his work as a teacher, a research worker and an active operative surgeon, he was a devoted member of this society who contributed significantly to the establishment of spinal units and the speciality of spinal injury in the United Kingdom.

He was born in 1913 in Canada, but his family originated in the United Kingdom and his father and grandfather had been professors at Liverpool University. He went to school at Winchester and then went to Balliol College Oxford where he obtained a first-class honours degree in physiology and biochemistry.

His medical training was interrupted by his participation in an expedition to the Himalayas. While there, he saw many deformed people, which raised his life long interest in the correction of spinal deformity. He returned to England and completed his medical training. During the Second World War, he served as a doctor aboard ship in the merchant navy. He was invalidated out of the service in 1943 and returned to work at the emergency medical service hospital at Winnick. He was then appointed as assistant surgeon at the Liverpool Royal Infirmary in 1946. In 1947, he joined the orthopaedic hospital at Oswestry and commenced his basic research work on the treatment of scoliosis and all aspects of spinal deformity. He was struck by the fact that the then conventional methods of treatment of scoliosis by posterior fusion could not cure the condition as the anterior part of the vertebra was not addressed by this operation, and to deal with this it required an anterior approach through the chest, initially extrapleurally and subsequently intrapleurally. He carried out this procedure and although this was contested at that time by other spinal surgeons, his approach has now been accepted as the definitive treatment.

He returned to India and stayed there for 3 years and set up a unit, which he insisted should be taken over and run by his colleagues. In 1955, he went back to England as the director of clinical studies at Oswestry and cowrote an important monograph on the treatment of tuberculosis of the spine. In 1963, he was appointed as a professor of orthopaedic surgery at Liverpool University.

He carried out basic research work on deformity of the spine delineating the mechanism of spinal injury and the importance of the ligaments in maintaining stability. He studied cadavers and showed that very great force was required to damage the cervical vertebrae by direct compression but if a rotational element was added, far less force was required to damage the disc and the joints. There is nearly always a rotational element in traumatic injury of the spine.

He was a very practical man and his work with regard to spinal injuries was of the greatest value in the early days. He was a member of the Society, and he wrote papers published in this journal on how patients with scoliosis developed paraplegia and conversely how patients with traumatic injuries could develop scoliosis. He wrote extensively including textbooks and articles for doctors and nurses on the management of spinal deformity. He recognized the importance of spinal injury units in the treatment of traumatic injuries and was responsible for the setting up of the spinal unit at Oswestry, and like so many things that he did, he immediately stepped aside and saw that competent people such as Terry Sweeney and Barry Jones took over the running of the unit. He remarked in this journal that people like himself who are parachuted in to the speciality recognized the necessity of full-time specialists in the field.

When I came to Liverpool at the beginning of my career, in 1965, the orthopaedic surgeon to the spinal centre was taken ill and unavailable, and I rang up Professor Roaf for help. Despite his extensive responsibilities and commitments, he immediately came out to operate on a patient with a sceptic hip.

He was a charming, unassuming modest man with a great sense of humour who was not afraid to speak his mind.

When the Royal College of Surgeons was making a visit to Liverpool, there was discussion as to what they could be shown as Liverpool's contribution. In desperation, orthopaedic surgeons suggested that they visit the accident unit at Walton hospital, entirely staffed by general practitioners. His dry voice from the back of the audience said: "Why not take them 40 miles further North to Preston so they could see how a proper accident unit should be run?'

$\mathrm{He}$ retained his clarity of thought and energy till the end of a long life. He went climbing in the Himalayas at the age of 85 . When I was carrying out my research on the history of the treatment of spinal injuries in the United Kingdom, I approached him for information and he immediately credited Tommy Nicholl rather than Frank Holdsworth, for his role in elucidating the stability of the spine in traumatic injuries.

He was a loyal, devoted man whose contribution in the United Kingdom, particularly to the establishment of paraplegic services, was of tremendous value at a time when the speciality was fighting for recognition. 